\title{
alphauille
}

\section{Cinemagoing as Spatially Contextualised Cultural and Social Practice}

Elisa Ravazzoli, Institute for Regional Development and Location Management, EURAC Research

\begin{abstract}
Cinemagoing as a sociocultural experience and the cinema theatre as a setting where that experience takes place are naturally linked to a certain notion of space. In fact, cinemagoing is a practice in which space is not only conceived and perceived but is also constructed; space and place are social constructs, always mediated by people's experience and sociocultural processes. Likewise, the space of the cinema theatre is not a given but is continuously produced, reconstructed and reconfigured by audiences. This article analyses the dialectic relations between the notions of space and place and the experience of cinemagoing as a spatialised social practice and a cultural experience; it also investigates the cinema theatre as a physical, symbolic and mental setting. Overall, the article offers a theoretical reflection on the multiple notions of space in relation to cinemagoing.
\end{abstract}

\section{Introduction}

This article offers a reflection on the opportunities that arise when using concepts from different disciplines (in this case, film studies, geography and sociology) for the investigation of cinemagoing as a spatialised social experience and cultural practice. The "critical turn" has seen film studies scholars become increasingly engaged with cinemagoing as a socially and geographically situated activity — as a practice that is shaped by the different times and places in which it occurs. Research on the cinemagoing experience is rooted in the subfield of "new cinema history", which embraces historical studies of film exhibition and experiences of cinemagoing (Maltby, Stokes, and Allen; Maltby, Biltereyst, and Meers). In order to grasp the intersections that constitute cinemagoing as intangible heritage in its spatial, social and cultural dimensions, the body of literature of human geography is particularly useful. In this article, concepts elaborated by Henri Lefebvre, David Harvey and Doreen Massey will be used to better interpret the complexity of the cinemagoing practice. The social sciences have been primarily concerned with the concept of space. Nevertheless, it is also useful for the purposes of this article to take into consideration existing theories and concepts that explain the symbolic and social dimensions of space and not only its material aspects.

On the one hand, the understanding of cinemagoing is linked to the relation between audience, film, cinema theatre and the space of the city and neighbourhood in which the cinema theatre is located. On the other hand, it relates to the meaning attached to the act of going to the cinema as a cultural fact and a social experience. Furthermore, cinemagoing is linked to the sensations, feelings, reactions and memories that this practice generates. Accordingly, this article investigates how concepts of space and place as well as notions of social experience and cultural practice help to interpret cinemagoing in terms of local specificities of places in time, and in relation to the unique human experience and memories that cinemagoing produces. In these terms, the power of geographical and social knowledge does not reside in the accumulation of data in inventories, but, rather, in the use of ideas, concepts and theories to explain and represent the world and its phenomena. These concepts help to better interpret cinemagoing as an 
intangible cultural heritage characterised by rituals, practices, representations, as well as cultural spaces. In this sense, the conventional conception of space that looks at it as an absolute space, as Euclidean geometry, does not help to interpret these phenomena; rather, space should be interpreted as an ongoing process in time. The article also reflects on how we physically create and shape spaces and places with our actions, and at the same time how spaces shape our behaviour and the cinemagoing experience. In this regard, the sociological and anthropological dimensions of space and the mutually interrelated relationship between space, identity and symbolic value will be discussed. The article is structured in sections. After the Introduction, in Section Two theoretical concepts of place and space (in which the audiences encounter the films) are analysed in order to interpret cinemagoing as a spatial practice. Section Three discusses the experience of going to the movies as a social practice and a cultural experience, as well as the meanings attached to it from a sociological perspective. Section Four explores the symbolic meaning ascribed to the cinema theatre as a spatial context in which cinemagoing takes place. Section Five discusses cinemagoing as a geographically situated social practice. Section Six investigates the relation between the individual, the environments and the perceptions that arise during the cinemagoing experience. The article ends with a discussion in Section Seven.

\section{Theoretical Concepts of Place and Space}

This section serves as an entry point into the debate on the relationships between space/place and people, how space/place is coproduced, perceived and experienced. Space and place are important concepts in the discipline of social science as they are fundamental to our understanding of the reality in which we live. The concepts of space and place have multiple meanings, developed in the course of time because of the wide-ranging variations and possibilities they imply metaphorically and conceptually. Generally, the concept of place tends to be related to a specific and unique location, which has distinct qualities; it refers to a particular experience and serves as reference point in people's lives, stimulating a sense of belonging. Conversely, the concept of space tends to be understood as abstract and more general; it refers to locations that have no specific meanings for their users.

Geographers' interest in the concepts of space and place relates mainly to the objects that are in space, to their relative position, to their interactions, as well as to the spatial relationships between people. Precisely, what most interest geographers are the ways in which place/space and people interact in complex, varied and dynamic ways. Gathering perspectives from sociology, geography and anthropology allows to present different conceptualisations of place and space. Important resources for the analysis within spatial theory are provided by the works of philosophers such as Henri Lefebvre, geographers such as David Harvey, Edward Soja and Doreen Massey, as well as by sociologists such as Anthony Giddens. In this section, I will briefly discuss the three notions of space conceptualised by Lefebvre, Harvey and Soja and the notion of place from Massey. As we will see, these theorists reject the idea that space is preconstructed, fixed, or a container of things, and embrace a relational view of space in which space/place is coproduced and reconstructed through people's actions and meanings.

The nature of space was central to the work of the French urban theorist Henri Lefebvre. His work The Production of Space, first published in France in 1974, prepared the ground for 
David Harvey, Manuel Castells and Edward Soja's spatial theories. Lefebvre sees space as a product of society and develops his conceptualisation of it based on a theory of everyday life. As a starting point of his reflection, he formulates the conceptual triad of space as a dialectical interaction between the spatial practice and perceived space, the representations of space or conceived space, and the spaces of representation or lived space. He elaborates a theory where spatial practices and social relations are constantly produced and reproduced and where space is not a given, but is continuously constructed and reconfigured. The spatial practice is the space produced by everyday practices, reinforced by routine for the production of spaces; it is the space of the lived experience and perception related to concrete feelings and sensations. It is the perceived space of society secreted by spatial practices. The representation of space is the space as it is conceived and represented by the individual and refers to the abstract representation mediated by common sense, such as maps, diagrams and pictures. It is the cognitive and ideological aspect of space, the conceived space conceptualised by scientists, planners, urbanists, technocrats and social engineers. The space of representation is the space of expression, of symbolic meanings, conveyed by images and symbols. It is a space that comes from the recognition that we do not live as material atoms in a material world; on the contrary, we have imaginations, feelings, emotions that strongly influence our relations in and with space. It is the lived space, as directly lived through its associated images and symbols. In articulating this set of space conceptualisations, Henri Lefebvre develops a theory that grasps the unity between the three fields of space: physical, mental, and social. He believes that space is a collection of objects that make actions possible, but it is also a field for action. In this regard, he offers the idea of space as both a structuring form and as a structured form, and suggests considering how the various modes of spatial production relate to each other.

Lefebvre's inspiration is particularly obvious in the work of David Harvey, who suggested a tripartite division of the concept of space in absolute space, relative space and relational space. Absolute space is represented as an immovable grid used to standardise measurement and open to calculation. It is the Euclidean space and, therefore, the space of all manner of cadastral mapping and engineering processes. It is the space where human calculation could flourish. Relative space is associated with the work of Einstein and to non-Euclidean geometry. The concept of relative space recall the fact that there are multiple geometries so all forms of measurement depend upon the frame of reference and the observer; in addition, it is impossible to understand space independently of time under this formulation and this mandates an important shift of language from space and time to space-time continuum. The relational space implies the idea of relations with specific things or processes in space. An event or a thing at a point in space cannot be understood by what exists only at that point, but it depends upon everything else going on around it. Like Lefebvre, he emphasised the social production of spaces and the impossibility to comprehend space without social actions, so phenomena are not only socially produced but they generate societal conditions.

Inspired by the echo of Lefebvre's tripartite division of space, in Thirdspace: Journeys to Los Angeles and Other Real-and-Imagined Places Edward Soja elaborated a spatiotemporal perspective on society and social life distinguishing between space as given and space as socially produced. He suggested a tripartite division of space in first, second and third space. The first space is characterised by material relations and practices; the second by images of space (conceived space); the third is the lived space encompassing both first and second space. Like 
Lefebvre and Harvey, Soja's work stresses the potentiality of space without looking at its emotional qualities or contemplating a distinction between the notions of space and place. No distinction is provided between a unique and specific place and an institutionalised and generalisable space. In this sense the notion of place seems to be more concrete than the notion of space. Most of the works on place agree with the idea that place consists in particular rhythms and that a feeling is attached to it. In her For Space, Doreen Massey defines space as simultaneity of stories distinct from place, which is instead a collection of those stories, articulations within the wider power-geometrics of space, whose character is a product of these intersections within that wider setting and of what is made of them. In the same work, Doreen Massey argues that place has numerous identities; this character comes to the fact that it is not frozen in time but that is rather a process always in transformation. According to Massey, space is not a flat surface across which we walk but is a collection of myriads of stories related to both the people that cross that space, and have their own stories, and the objects that exist in it in a specific period. This conception of space as a place refers to the place-identity theories, to the conjunction between place and identity. Precisely, it concerns the meanings of places for the inhabitants and users, and how these meanings contribute to individuals' conceptualisations of the self. The quality of space and place becomes the focus of microsociology and, in particular, of the work of Anthony Giddens, who refuses to consider space and time as merely boundary conditions of action (see also Urry). According to Giddens, space is not only experienced through the body, but has also an impact on the body itself. Space is not the product of actions but it structures actions as well. The concept of place is central also to the work of Yi-Fu Tuan, who argues that place has substance, is a unique special thing, a complex ensemble rooted in the past and growing into the future, that it has a history and a meaning.

The existing conceptualisations of space and place provide a rich theoretical framework within which to develop a debate on cinemagoing as a spatialised cultural and social practice. These categories suggest different modalities to understand the significance of space, both in physical and representational terms, and in terms of lived experience. While in the absolute and conceived space everything is clear and measurable, things are more complicated in the relative and relational spaces, where many cultural and social processes occur. What is necessary to mention is that space and place are the products of social actions and interactions generated by people, who are directly involved in the construction of space. Actions that happen in the absolute space, although this can be measured, only make sense in relational terms, because they are always constructed and mediated by people, representations, symbols, concepts and experiences. The absolute and measurable space of Euclidean geometry alone cannot capture the complexity and variety of human conceptions of space and time, for it only supports an understanding of the contextualised nature of space - but space is given a meaning when it is measured in terms of processes, practices and activities.

\section{Cinemagoing as Cultural Practice and Social Experience}

This section discusses cinemagoing as a form of cultural practice, also highlighting the significance of cinema as a social experience. Going to the cinema to watch a movie has always been considered a discrete component of culture and a popular leisure activity that can be compared to going to a concert, a theatre or a museum. The tradition of going to the cinema is 
based on a culturally transmitted practice that resulted from the time before television, video, DVD and the Internet, and in which the film is considered as a significant cultural product able to satisfy the audience's needs to have a cinematic experience. In Western cultures, people, often the entire family, used to dress up, leave the house and walk to the cinema theatre. Besides being an institutionalised cultural practice and an opportunity for leisure and consumption, cinemagoing has also been seen, especially in the 1950s and 1960s, as an established form of social entertainment. Indeed, the wider context of cinemagoing offered many opportunities for social interactions. These, of course, occurred mostly outside the screening of the film and the cinema theatre, and included activities such as travelling to and from the theatre, and pre- or post-screening get-togethers and debates. In this respect, the cinema theatres were regarded as important places in which residents of varying ages, interests and backgrounds could meet and interact in a relaxed and intimate local setting. What is useful to underline is that the experience of cinemagoing encompassed much more than watching the film; what mattered for people was not only the film itself, but also the venue and what happened before and after the screening of the film. As argued by Morley, "there is more to cinemagoing than seeing films ... There is going out at night and the sense of relaxation combined with the sense of fun and excitement. Rather than selling individual films, cinema is best understood as having sold a habit, a certain type of socialized experience" (157-8).

Changes to the geography of cinema, from traditional city-centre theatres to the cinemas in shopping malls, have affected the routines of cinemagoers (Aveyard). Not only cinema theatres in the Western culture and in urban areas have become more impersonal, but they also no longer offer the range of get-together opportunities that cinema theatres offered in the past. Nevertheless, cinemagoing remains a significant part of the social and cultural life of cities, a recurrent social practice that engages communities at a broader level, still providing a site for social interaction (e.g. post-film debates). Therefore, the social and cultural background that constitutes the whole cinemagoing experience is still of relevance, especially for the capacity of the cinema venue and its annexed spaces to produce different types of social and material relations, as well as to generate positive spatial experiences. For these reasons, cinema theatres are not only places designed for the purpose of watching films; on the contrary, they are places for people to gather, for social encounters and material relations. In some rural settings and small communities, cinema theatres are not only places for social and cultural life, but also places where audiences enjoy an "intimate atmosphere, the feeling of familiarity and personal recognition", thus experiencing a sense of local place belonging (Aveyard 299).

\section{Cinemagoing as Geographically Situated Practice}

This section discusses cinemagoing as a geographically situated practice connected with the social and cultural rhythms of everyday life in specific locations. Particularly, the article here seeks to reflect on the diversity of situations in which people watch movies and the extent to which the meaning of these experiences are shaped by geographic location. It discusses the way space is shaped and created by the audience, as well as how space affects our social actions and contribute to create unique experiences. 
The role of geography in shaping cinemagoing has been clearly demonstrated in a number of scientific works (Hubbard; Arrowsmith and Verhoeven; Klenotic; Arrowsmith, Verhoeven, and Davidson). Besides being a sociocultural practice, cinemagoing is, foremost, a geographically situated experience. Even though today the cinematic experience increasingly happens in private homes and on mobile devices, cinema theatres as physical setting continue to be an important spatial context in which the audience view films. Cinemagoing involves spaces that go beyond the unique space of the cinema theatre, to include streets and public spaces as well as objects that are nearby and that belong to the neighbourhood (e.g. bus stop, cafes and parks). They all together contribute to generate a contextualised spatial experience. The movement from private spaces (e.g. home) to public spaces (e.g. cinema theatre) puts people in contact with each other as well as with material objects. In this sense, cinemagoing as a spatialised practice shapes the spaces of the cinema theatres, the spaces of the neighbourhood and of the city in the same way as the cinema theatres, the neighbourhoods and the city shape the experience and the perceptions that are involved in cinemagoing.

On the one hand, analysing the internal and external spaces involved in cinemagoing means to consider that each space has its own history and is embedded in wider economic, social, ethnic and cultural backgrounds; thus, spaces have the power to influence actions and meanings of the individual experiences of the audience. On the other hand, analysing cinemagoing in spatial terms also means to consider the act of physically experiencing the space. This entails many actions: going to the cinema theatre, crossing spaces, walking streets and neighbourhoods, moving towards the destination, and being in a public space. With these actions of crossing and moving through spaces as well as staying in space, people assign meanings to spaces, thus designating their social and factual dimensions. The dialectic between private and public spaces is especially interesting and, precisely, the movement from the private space of the home to the public space of the cinema theatre transforms the individual experience of going to the cinema into a social practice in public spaces. In this regard, the concept of locality is well suited to explain the specificities of place - the individual characteristics of the cinema theatre, the features of the town in which the theatre is located-and how these characteristics shape the meanings of cinemagoing. Following Lefebvre's conception of space, space is a social construct always mediated by people's experiences, by societal processes, and created by people's actions and interactions. The relationship between cinemagoing and space is therefore bidirectional. On the one hand, space and its objects influence the experience of cinemagoing. This aspect refers to the way elements that are located in space generate feelings and emotions in people. On the other hand, space is produced and mediated by people's experiences and actions. This aspect refers to the way people move in space, the types of streets they choose to cross, and how people act in space; all these contribute to define specific characteristics of space.

Considering cinema as a spatial practice embedded in social, cultural and historical constructs enables us to discuss the embedded spatiality of cinema in the production of space and place, putting the cinema in its multiple dimensions in relation to one of the classical concepts in geography: the concept of space. 


\section{The Cinema Theatre as Symbolic Place of Cinemagoing}

This section explores the symbolic meaning attached to the cinema theatre as a spatial context in which the audience encounter the film and where cinemagoing as a spatial practice takes place; it also discusses the relation that arises between space, symbolic value and identity. The starting point of the discussion is that the space of the cinema theatre is not a given space but is continuously produced, reconstructed and reconfigured. Not only the particular places of the cinema theatre are relevant for the cinemagoing experience, but they are also considered as integral parts of the urban space, which also participate in the definition of a local geography (Cladel et al.; Creton). Creating spaces is an important element of any given social structure; once spaces are created, they impose themselves on their members through the values they manifest or through the values attributed to them. According to Edward Hall, humans have an intrinsic need to experience their physical and social environments through direct encounters with places that are associated with multiple tactile, olfactory, visual and auditory cues. Thus the cinema theatre is, first of all, a physical site of spatial exchange; the public space where the cinemagoers experience a social and cultural practice. Second, it is a space that contributes to the preservation of a collective memory, as it constitutes a prevalent sociocultural practice linked to a specific place, which acts as a common reference point for numerous people (Guy). It is considered as an integral part of urban space that participates in the definition of a local geography of cinemagoing. Furthermore, and more importantly, the cinema theatre is a space with strong symbolic value that means something to a group of individuals, in such a way that it contributes to create identity.

Beyond its practical uses and physical character, a place has a social content that can be expressed in symbolic terms, which are determined by the historical circumstances in which they are used. For this reason, places have different meanings for different groups of people through time. A symbol is something concrete (e.g. building, room) that communicates an intangible reality (e.g. a value, a feeling, etc.). The symbolic dimension of space can be expressed in different forms: it can be linked to a group of social values; it can be related to meanings expressed by social usages; it can be related to sensations and feelings generated by the experience. Because spatial situations are built through experiences and interpreted through symbols, and the physical environment is a part of the social learning, any space has a symbolic value in the way it is designated and represented, and supports the social structure of a group.

According to Jérôme Monnet, the symbol is a materiality that conveys the immaterial, a visible thing that shows the invisible, and a gesture that signifies a value. Like all signs, symbols have meanings or signify, which is to say that they carry the meanings with which an individual or a group has endowed them. Unlike other signs, symbols are recognisable on account of one particular feature, which is that they are concrete realities, objects or physical actions, the factual existence of which is relatively independent from the meaning that is attributed to them. Symbolisation is "one of the major factors differentiating space into places, since this process endows a portion of space with a name, an identity, a permanence, a reason for existing, and a particular relationship with certain values and meanings" (Monnet). According to what just said, cinema theatres are symbolic places. Normally speaking, all places have a symbolic dimension and a unique character. While this is true, it should be added that some places are more symbolic than others. Some places are more symbolic than others because they entail a social empathy 
around a shared meaning and because they are socially recognised by authorities, citizens and individuals. In the case of the cinema theatres, they can be considered as symbols of leisure and of expression of culture; however in the past they have been also considered as symbols of social exclusion or racial segregation (Allen). This was particularly true in the United States or in Australia since the 1940s, when Coloured people and Aborigines were excluded from theatres, restaurants and public spaces and were allowed to access certain areas and not others, mainly occupied by Whites. Coloured people did not have the right to go to the movies as the Whites did, being excluded from cinema and also segregated within cinema (Nugent).

In the course of time, the space of the cinema theatre has changed radically; actually, the space of the cinema theatre changes considerably also during the day. This is because it is the setting of different social and cultural experiences, which turn it from a physical, material, abstract, empty space to a vibrant, social, lived cultural space during the screening of the film or during social and entertainment events. Overall, cinema theatres have a strong symbolic value in society. They are symbolic places and common places because they are understood by all, which is to say their symbolic dimension does not escape anyone inside the group, and because they are shared by all, which is to say their symbolic dimensions gather all.

\section{Perceptions and Feelings of Space}

This section seeks to discuss how humans interpret information through perceptions and senses, how meaning is attached to spaces/places and how they are experienced and lived concretely. Ecological psychology demonstrated that there is a strong relation between humans and their environment (Barker; Lewin). More precisely, the individual and his/her environment are coproduced in the way that specific places generate particular experiences. Moreover, experience, sensations, feeling, perceptions and conceptions are the ways by which we come to know the world. Experiences lead people to recognise particular elements in space; perceptions foster place attachment and enable the development of a sense of place; touch, movement and thought combine to define the characteristics of places. People and space are interconnected in the sense that people come to identify themselves and their lives with places and spaces they feel and use, so that the relation between them is mainly a matter of perception and experience. Although behavioural patterns vary enormously, they are all rooted in the relation between the body and the space (Tuan). In this regard, Kevin Lynch argues that:

there is more than the eye can see, more than the ear can hear, a setting or a view waiting to be explored. Nothing is experienced by itself, but always in relation to its surroundings, the sequences of events leading up to it, the memory of past experiences. ... Every citizen has had long associations with some part of his city, and his image is soaked in memories and meanings. (1)

The cinemagoing experience depends not only on what happens in the place; it is also influenced by people's perceptions and feelings of space. Space is both material and immaterial; it is characterised by objects but also by a complex tissue of perceptions, emotions, events and processes. Each space and place evokes certain feelings and images that are linked to perceptions and emotions. Indeed, in the construction of space, perceptions play an important role. 
Perceptions are related to the circumstances that people not only see but also smell, hear and feel and to the atmosphere of the space in which they are situated. Perceptions describe the multiple ways in which people receive information from their surroundings, enabling them to know their environment. In this process, all senses are involved and, in experiencing space, what is heard and what is smelt influence space construction and can be considered as a perceptual activity of bodily sensing.

In practical terms, the music of the film contributes to the formation of place as well as the smells of places contribute to the perception of and attachment to place. Moreover, nothing is experienced by itself, but always in relation to its surroundings and to the memory of past experiences. The way space is perceived and subsequently conceived relies on a mix of multiple elements. Conceiving space consists in understanding the environment through immediate sensory experience together with memories and experiences from the past. The feelings developed by everyday practices and coming from the experience of physical spaces generate a sense of space belonging that encourages place attachment, which is the way people are bond to places. This feeling is explained as an emotional mechanism that translates the environmental stimuli and cultural elements into a code of social interaction, which in turn makes the individual feel and live in harmony with the environment, and attached to a place. All this information together suggests that there is an active relation between the environment and people; every person creates and defines the space and place in which he or she lives. Between people and the environment there is a complex dynamic exchange in which the environment informs human knowledge and human experience shapes the way in which the environment is known, as already mentioned in Section Three.

\section{Discussion}

This article aimed to explore the relationships between the audience and the spaces in which the cinemagoing experience takes place, and to consider the active role individuals play in creating the environments in which they live. It also aimed to offer a theoretical understanding of the interactions between spaces/places and the audience, precisely, the ways in which spaces/places are produced and reconstructed, and the ways in which meanings are attached to cinemagoing. The exercise of working with different notions of space in the framework of the cinemagoing experience stressed the need to consider cinemagoing and film-related processes as spatial practices embedded in a concept of space that is at once physical, relational, experiential and sensorial and that is thus continually produced, conceived and lived by people. The examination of the interrelationships existing between different conceptions of space (perceived, conceived, lived, symbolic and sensorial) was essential to reach a comprehensive understanding of different meaning(s) of space.

The relations between space/place and people are different: social, cultural, physical, psychological. In this article I considered the cultural and social dimensions, as well as the symbolic one, including both perceptions and emotions in the discussion. The activities people are engaged in, the meanings they give to places, the opportunities open to them are all informed by the complex dynamics elaborated by the human being in place and space. This is to say that individuals have an active role in the process of space production but, in the same way, 
cinemagoing connects more broadly with wider social, cultural and economic conditions. Consideration of the ways in which humans physically shape and create spaces with their actions and, at the same time, of how space shapes human behaviour and evokes feelings and emotions is relevant when interpreting cinemagoing practices. Reading and picturing the multiple meaning(s) of spaces enabled us to interpret space in both analytical and emotional terms, which implies exploring the features of both the absolute and conceived space and the experienced, symbolic and representational space. This approach suggested the idea that space, being a social, cultural, symbolic and sensorial construct to all effects, is a container of people's experience, representations and processes. Indeed, space can be considered as a palimpsest and a complicated tissue of events, objects and processes in a certain time dimension.

What has not been discussed explicitly is the strong relation between space and time. We take for granted that any event in space happens in a particular timeframe. Thus, cinemagoing is not only spatially contextualised, but is also part of a certain temporal dimension, so that it is not possible to interpret spatial phenomena independently of time. The time-space relation or the notion of spatio-temporality is another category that informs the comprehension of complex phenomena like cinemagoing, and that can be the object of future research on the topic.

\section{Works Cited}

Allen, Robert C. "Reimagining the History of the Experience of Cinema in a Post-Movie-Going Age." Media International Australia 139.1 (2011): 80-7. Print.

Arrowsmith, Colin, and Deb Verhoeven. "Visual Methods for Showing Cinema Circuits at Varying Temporal and Spatial Scales." Geospatial Science Research Symposium (GSR_1), Melbourne. 12-14 December 2011. Conference paper.

Arrowsmith, Colin, Deb Verhoeven, and Alwyn Davidson. "Exhibiting the Exhibitors: Spatial Visualization for Heterogeneous Cinema Venue Data." The Cartographic Journal 51.4 (2014): 301-12. Print.

Aveyard, Karina. Lure of the Big Screen: Cinema in Rural Australia and the United Kingdom. Bristol: Intellect, 2015. Print.

---. "The Place of Cinema and Film in Contemporary Rural Australia." Participation: Journal of Audience and Reception Studies 8.1 (2011): 294-307. Print.

Barker, Roger. Ecological Psychology: Concepts and Methods for Studying the Environment of Human Behaviour. Stanford: Stanford UP, 1968. Print.

Bourdieu, Pierre. Outline of a Theory of Practice. Trans. Richard Nice. Cambridge: Cambridge UP, 1977. Print. 
Cladel, Gérard, Kristian Feigelson, Jean-Michel Gévaudan, Christian Landais, and Daniel Sauvaget, eds. Le cinéma dans la cité. Paris: Éditions du Félin, 2001. Print.

Creton, Laurent. Économie du cinéma: perspectives stratégiques. Paris: Nathan, 2001. Print.

Giddens, Anthony. The Constitution of Society: Outline of the Theory of Structuration. Cambridge: Polity Press, 1984. Print.

Guy, Jean-Michel. La culture cinématographique des Français. Paris: La Documentation Française, 2000. Print.

Hall, Edward T. The Hidden Dimension. New York: Doubleday, 1966. Print.

Hubbard, Phil. "Going Out (of Town): New Geographies of Cinema-going in the UK." 2004. Web. 22 June 2016. <http://www.nottingham.ac.uk/scope/documents/2004/february2004/hubbard.pdf>.

Klenotic, Jeffrey. "Putting Cinema History on the Map: Using GIS to Explore the Spatiality of Cinema." Explorations in New Cinema History: Approaches and Case Studies. Eds. Richard Maltby, Daniel Biltereyst, and Philippe Meers. Malden, MA: Wiley-Blackwell, 2011. 58-84. Print.

Lefebvre, Henri. The Production of Space. Trans. Donald Nicholson-Smith. Cambridge: Blackwell, 1991. Print.

Lewin, Kurt. "Psychological Ecology." Field Theory in Social Science: Selected Theoretical Papers, ed. Dorwin Cartwright. London: Social Science Paperbacks, 1952. 289-300. Print.

Lynch, Kevin. The Image of the City, Cambridge, MA: MIT Press, 1960. Print.

Maltby, Richard, Daniel Biltereyst, and Philippe Meers. Explorations in New Cinema History: Approaches and Case Studies, Cambridge: Wiley-Blackwell, 2011. Print.

Maltby, Richard, Melvyn Stokes, and Allen C. Robert. Going to the Movies: Hollywood and the Social Experience of Cinema. Exeter: Exeter UP, 2007. Print.

Massey, Doreen. For Space. London: Sage, 2005. Print.

Monnet, Jérôme. "The Symbolism of Place: A Geography of Relationships Between Space, Power and Identity." Trans. Angéla Verdier. Cybergeo: European Journal of Geography, Political, Cultural and Cognitive Geography 562 (2011). Web. 22 June 2016. < https:// cybergeo.revues.org/24747>.

Morley, David. Television, Audience and Cultural Studies. London: Routledge, 1992. Print. 
Nugent, Maria. "Every Right to be There: Cinema Spaces and Racial Politics in Baz Luhrmann's Australia." Australian Humanities Review 51 (2011): 1-11. Web. 22 June 2016. <http:// www.australianhumanitiesreview.org/archive/Issue-November-2011/nugent.html>.

Soja, Edward. Postmodern Geographies: The Reassertion of Space in Critical Social Theory. New York: Verso, 1989. Print.

---. Thirdspace: Journeys to Los Angeles and Other Real-and-Imagined Places. Cambridge: Blackwell, 1996. Print.

Tuan, Yi-Fu. Space and Place: The Perspective of Experience. Minneapolis: U of Minnesota P, 2001. Print.

Urry, John. "Time and Space in Giddens' Social Theory." Giddens' Theory of Structuration: A Critical Appreciation. Eds. Christopher Bryant and David Jary. London: Routledge, 1991. 160-75. Print.

\section{Suggested Citation}

Ravazzoli, Elisa. "Cinemagoing as Spatially Contextualised Cultural and Social Practice." Alphaville: Journal of Film and Screen Media 11 (Summer 2016): 33-44. Web. ISSN: 20094078.

Elisa Ravazzoli is a human geographer working as a senior researcher at the Institute for Regional Development and Location Management of the European Academy of Bozen/Bolzano (EURAC Research). Her main research interests include the examination of cultural, environmental and societal phenomena and how they relate to space and time, mostly using Geographical Information System spatial analysis as the main instrument of investigation. Her most recent publication of interest is "The Geography of Film Production in Italy: A Spatial Analysis Using GIS" (in Locating the Moving Image: New Approaches to Film and Place, eds. Julia Hallam and Les Roberts, 2013). 